\title{
A Systematic Review of the Main Factors that Determine Agility in Sport Using Structural Equation Modeling
}

\author{
by \\ Vladimir Hojka1, Petr Stastny ${ }^{1}$, Tomas Rehak ${ }^{1}$, Artur Gołaś2, \\ Aleksandra Mostowik², Marek Zawart ${ }^{3}$, Martin Musálek ${ }^{1}$
}

\begin{abstract}
While tests of basic motor abilities such as speed, maximum strength or endurance are well recognized, testing of complex motor functions such as agility remains unresolved in current literature. Therefore, the aim of this review was to evaluate which main factor or factor structures quantitatively determine agility. In methodological detail, this review focused on research that explained or described the relationships between latent variables in a factorial model of agility using approaches such as principal component analysis, factor analysis and structural equation modeling. Four research studies met the defined inclusion criteria. No quantitative empirical research was found that tried to verify the quality of the whole suggested model of the main factors determining agility through the use of a structural equation modeling (SEM) approach or a confirmatory factor analysis. From the whole structure of agility, only change of direction speed (CODS) and some of its subtests were appropriately analyzed. The combination of common CODS tests is reliable and useful to estimate performance in sub-elite athletes; however, for elite athletes, CODS tests must be specific to the needs of a particular sport discipline. Sprinting and jumping tests are stronger factors for CODS than explosive strength and maximum strength tests. The authors suggest the need to verify the agility factorial model by a second generation data analysis technique such as SEM.
\end{abstract}

Key words: change of direction, testing, sports training, motor abilities.

\section{Introduction}

Testing of motor abilities is crucial for monitoring of sport training and talent identification. While the tests of basic motor abilities such as speed, maximum strength or endurance are well recognized, testing of complex motor abilities such as agility remains unresolved in the current literature. The term agility itself has undergone changes, resulting in the current definition: "the ability to change speed and direction of a movement rapidly and accurately" (Jeffreys, 2011; Sheppard et al., 2014), usually in response to a highly specific stimulus. The specific stimuli include different situations during sport

competitions that vary in intensity, with the condition of space-time uncertainty being met. The term "agility" has evolved significantly, with the main factors determining agility also changing. The most current model divides agility into cognitive, physical and technical factors (Young et al., 2015), instead of the perceptual one with decision-making factors and change-ofdirection speed (CODS) factors that were used in the previous model (Young et al., 2002; Sheppard and Young, 2006; Mikołajec et al. 2013; Sheppard et al., 2014) (Figure 1). The result of this inconsistency created additional specific terms to

1 - Charles University in Prague, Faculty of Physical Education and Sport.

2 - Department of Theory and Practice of Sport; The Jerzy Kukuczka Academy of Physical Education in Katowice; Poland.

3 - Department of Team Sport Games; The Jerzy Kukuczka Academy of Physical Education in Katowice; Poland. 
describe specific parts of agility, such as reactive agility, quickness or reactiveness. However, no quantitative description is currently available to describe and test agility itself or its partial factors.

Empirically accepted tests of agility have been screened to determine their relationships between each other and to specific subtests, which delineate any agility sub-factors. For example, the 505 agility test was highly correlated with the " $\mathrm{L}$ " agility test $(r=0.73)$ and moderately with the reactive agility test $(r=0.50)$ (Gabbett et al., 2008), and the factor of straight sprinting represented by the $36 \mathrm{~m}$ dash correlated with the "T" agility test $(r=73)$ (Pauole et al., 2000). In these cases, the authors determined whether the performance on one test was related to another, indicating that if an athlete performed well during one test, he may perform well in another test. These types of findings resolve the specific relationships among agility sub-tests and are useful to explain the role of specific tests in sports training. However, this approach does not offer an explanation of the structure of the main factors that determine agility; for example, how does one explain how significantly the $36 \mathrm{~m}$ dash, "L" agility test or reactive agility test predicts overall agility? Moreover, the choice of an agility test should clearly fit into an agility structure and not cross between its sub-factors with unknown factorial strengths; therefore, it is currently not known whether five or ten tests are enough to estimate agility performance. It may be advantageous to reduce the seemingly infinite number of agility tests when aiming to determine agility performance. Moreover, it may be possible to test independent sub-factors of agility that can effectively estimate agility performance. The empirical aspect of agility testing is necessary as the choice of the test can differ with respect to the specificity of the sport discipline or performance level.

Since the relationships among individual agility tests are already known for numerous sports and athletic populations (Sheppard et al., 2014; Young et al., 2015), quantifying to what extent the underlying sub-factors of agility (i.e., leg strength, change-of-direction speed, linear sprint speed, anthropometrics and other quantifiable variables) directly impact agility performance could be useful. Although uncommon within sport science literature, structural equation modeling (SEM) is common within behavioral research (MacCallum and Austin, 2000; McNeill et al., 2006; Marsh et al., 2010). SEM seeks to explain the relationships between independent and dependent variables, which can be either continuous or discrete (Schreiber et al., 2006). From this perspective, SEM is often understood as a combination of factor analysis and multiple regression analysis or path analysis (Hox and Bechger, 1998; Ullman, 2001; Magiera et al. 2013). Therefore, SEM is often used in situations when studies aim to empirically establish the structure of a certain behavioral domain without any evidence or information about relationships and their strengths (Kline, 2011). For example, "intelligence" is a latent variable that does not have an observational or quantifiable result; rather, it is inferred based on quantifiable data from the underpinning subfactors of intelligence that have observational outcomes based on previously established testing norms (spatial, kinesthetic, musical, linguistic, etc.). Much like intelligence, agility is a latent variable with underlying sub-factors (leg strength, linear sprint speed, reaction time, etc.). Therefore, the evidence and information about relationships between manifest and latent variables are important for modeling of agility structure and further development of valid and reliable tests.

The models of agility's main underlying sub-factors (Jeffreys, 2011; Sheppard et al., 2014; Young et al., 2014, 2015) were specifically based on the empirical approach, while the explanation and application of the agility tests were derived mainly from the following: 1) validity and reliability of indicators that were considered criteria of agility performance; 2) correlations revealed between these indicators and other manifest variables such as the " $\mathrm{T}$ " agility test, straight sprint, countermovement jump or skinfold thickness (Gabbett et al., 2008; Hachana et al., 2013; Pauole et al., 2000; Raya et al., 2013). Therefore, the aim of this review was to determine which main factors could quantitatively determine agility performance. In an attempt to explain and describe the relationships between manifest and latent variables and distinguish them from the underlying factors of agility, different approaches were used, such as principal component analysis (PCA), factor analysis and SEM. The results provide an overview of agility 
structure modeling, shed light on scientifically unresolved portions of defined agility structures and discuss directions for future research.

\section{Material and Methods}

This study utilized the Preferred Reporting Items for Systematic Reviews and Meta-Analyses (PRISMA) (Moher et al., 2010) guidelines during the search (Figure 2). The database search was conducted in May 2016, and the Web of Science, PubMed and Scopus databases were screened from 1976 to 2015. The search formula included "agility OR change of direction".

The title and abstract screening was focused on studies that included tests of agility or CODS, testing agility or CODS, relationships between agility and cognition, the role of agility in team sport games, agility or CODS in relation to sport performance and any factors influencing agility. The selection criteria were as follows: (1) the abstract and the article itself were published in a reviewed journal in English; (2) the topic was exclusively concerned with agility or CODS in sport; (3) the aim of the study was to explain or improve agility performance, describe the agility structure or recognize the main factors determining agility; and (4) the participants of the research studies were recreational, collegiate, amateur or professional athletes.

A team of independent evaluators was appointed for full-text screening to choose relevant research studies and hand search through the reference lists of articles and books. Each evaluator was tasked with reviewing the articles and making a decision on accepting the articles based on the following inclusion criteria: (1) the number of study participants reached the minimal biological sample (30 people) and (2) the agility factorial structure or its sub-factors were evaluated by either PCA, factor analysis or SEM.

\section{Results}

The database search resulted in 2260 studies after removing duplicates during title and abstract screening. A total of 60 papers were followed up by selection criteria for full-text screening (Figure 2). Finally, four research studies that focused on CODS met the defined inclusion criteria. Using a desired methodological approach, no quantitative empirical research was found that attempted to verify the quality of the whole suggested model of the main factors determining agility using the SEM approach or confirmatory factor analysis. During full-text screening of numerous studies concerning agility, factorial models were rejected because they reported only correlation coefficients across different tests and did not apply appropriate statistical methods. Moreover, these studies had already been summarized in previous reviews (Sheppard et al., 2014; Young et al., 2015). One study that focused on the "latent structure of agility" (Metikoš et al., 2003) was rejected because it was not available in English. Additionally, other studies that used multiple regression (MR) were excluded (Delextrat et al., 2015; Hachana et al., 2013; Spiteri et al. 2014b). Although MR principles are directly linked to the SEM approach, its core is in analyzing the observed variables only (Tabachnick et al., 2001). Therefore, MR does not evaluate relationships among multiple dependent factors (tests) and cannot recognize the level and strength of their dependency in structural models simultaneously (Muthén and Muthén, 2010).

The selected studies are summarized in Table 1. Three of the studies used PCA with KaiserGuttman criterion and one study used factor analysis (exploratory approach) (EFA) along with regression analysis. Three studies included collegiate athletes and one study involved elite soccer players.

\section{Discussion}

Only 4 studies out of 60 relevant titles discussing agility involved research attempting to determine the main factorial model of agility, which means that the current understanding of agility is based strongly on the empirical approach rather than a quantified hierarchy of manifest variables or tests. This result seems to be appropriate because the concept of agility arose from empirical experiences and practices. Moreover, it must be emphasized that three of the studies used a PCA approach. Although PCA belongs to the family of exploratory techniques, it is not based on a common factor model (Fabrigar et al., 1999). Rather, PCA is focused on the amount of variance explained by manifest variables instead of an explanation of the correlations between them. Therefore, PCA is appropriate as a data reduction technique, but not for verifying relationships between latent variables within an evaluated structure. 

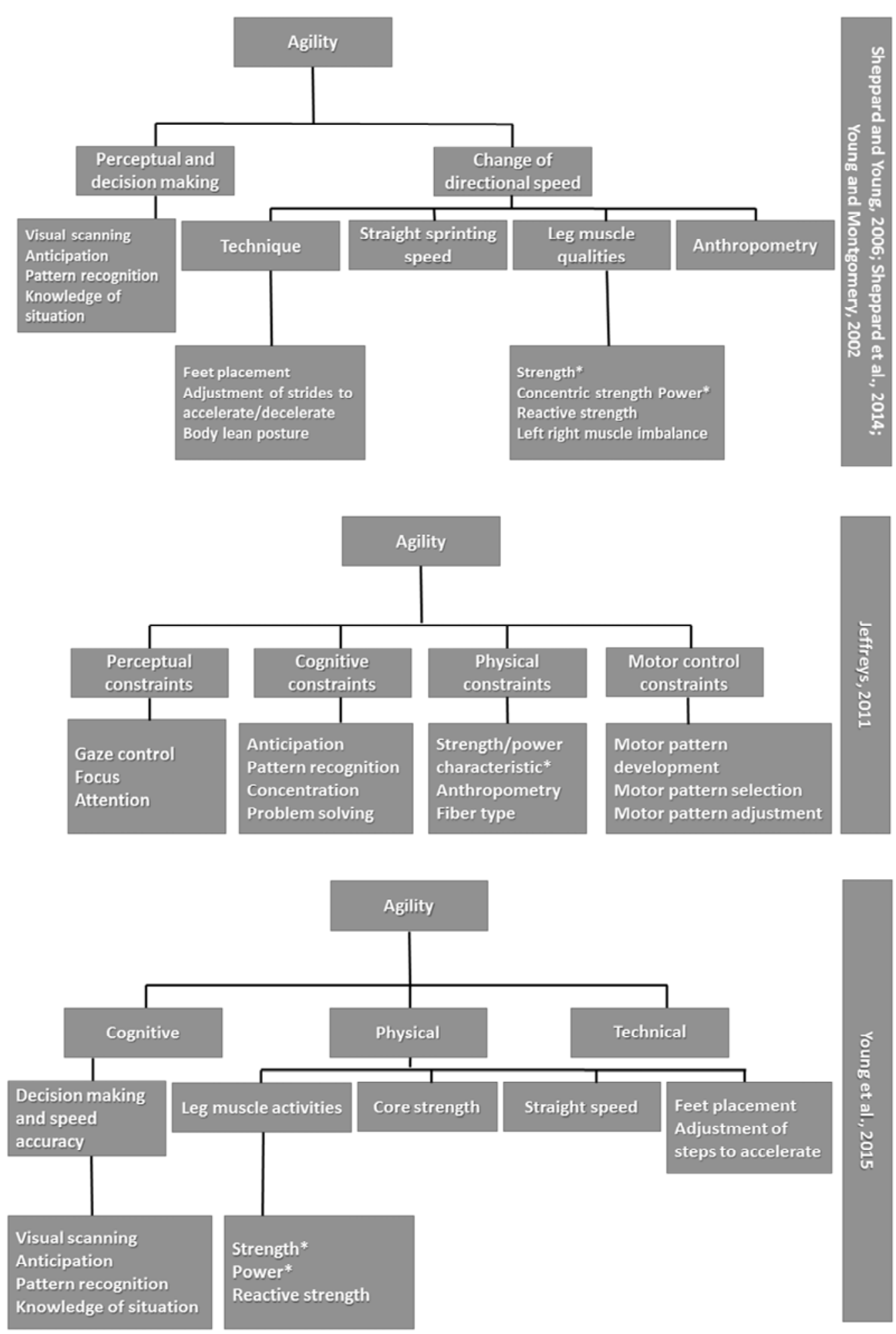

\section{Figure 1}

Models of main factors determining agility

*factors evaluated by principal component analysis or factor analysis - exploratory approach. 


\section{Table 1}

Articles evaluating the agility factorial structure or change of direction

\begin{tabular}{|c|c|c|c|c|}
\hline Authors & Participants & Tests performed & Statistics & Result \\
\hline $\begin{array}{l}\text { Stewart et al., } \\
2014\end{array}$ & $\begin{array}{l}\mathrm{n}=44, \\
24 \text { males, } \\
20 \text { females, } \\
\text { Age: } 16.7 \pm 0.6 \\
\text { years, } \\
\text { College* } \\
\text { (invasive games) }\end{array}$ & $\begin{array}{l}\text { Illinois } \\
\text { L-Run } \\
\text { Pro-Agility } \\
\text { T-test } \\
\text { 5-0-5 agility }\end{array}$ & $\begin{array}{l}\text { PCA, } \\
\text { Kaiser- } \\
\text { Guttman } \\
\text { criterion }\end{array}$ & $\begin{array}{l}\text { The PCA resulted in the extraction of } \\
\text { one significant component that } \\
\text { explained } 89.52 \% \text { of the total } \\
\text { variance. All selected tests were } \\
\text { positively and strongly correlated }(r= \\
0.84-0.89) \text {. It was concluded that all } \\
\text { tests were highly reliable and valid } \\
\text { measures of CODS. }\end{array}$ \\
\hline $\begin{array}{l}\text { Salaj and } \\
\text { Markovic, } 2011\end{array}$ & $\begin{array}{l}\mathrm{n}=87, \\
\text { male college } \\
\text { athletes, } \\
\text { Age: } 19.3 \pm 1 \\
\text { years }\end{array}$ & $\begin{array}{l}\text { Skinfold thickness } \\
\text { SJ, CJ, SLJ, LS } \\
\text { Sprint } 5 \mathrm{~m}, 10 \mathrm{~m} \\
\text { Sprint } 20 \mathrm{~m} \\
\text { Flying sprint } 20 \mathrm{~m} \\
\text { 18-m shuttle run } \\
\text { Figure-of-eight } \\
\text { run } \\
\text { DJ } 30,50 \mathrm{~cm} \\
\text { Maximal hopping } \\
\text { in place - } 6 \\
\text { rebounds }\end{array}$ & $\begin{array}{l}\text { PCA, } \\
\text { Kaiser- } \\
\text { Guttman } \\
\text { criterion }\end{array}$ & $\begin{array}{l}\text { The PCA revealed a relatively simple } \\
\text { and consistent structure consisting of } \\
4 \text { separate factors that explained } \\
\text { nearly } 80 \% \text { of the variance of the } \\
\text { applied tests. The factors appeared to } \\
\text { correspond to the sprinting ability, } \\
\text { concentric/slow SSC jumping ability, } \\
\text { fast SSC jumping ability and CODS } \\
\text { ability. }\end{array}$ \\
\hline $\begin{array}{l}\text { Markovic et a } \\
2007\end{array}$ & $\begin{array}{l}\mathrm{n}=168 \\
\text { male } \\
\text { Age: } 21 \pm 2 \text { years }\end{array}$ & $\begin{array}{l}\text { 18.3-m shuttle run } \\
\text { Slalom run } \\
\text { SJ, CJ, SLJ, LS } \\
\text { DJ } 30,50 \mathrm{~cm} \\
\text { Isometric Sq, } \\
1 \text { RM back Sq } \\
\text { Weighted Sq jump } \\
\text { force } \\
\text { Maximal hopping } \\
\text { in place }-5 \\
\text { rebounds }\end{array}$ & $\begin{array}{l}\text { EFA, } \\
\text { regression } \\
\text { analysis } \\
\text { p }\end{array}$ & $\begin{array}{l}\text { Factor analysis of all tests revealed } \\
\text { four independent factors: explosive } \\
\text { strength, elastic strength, CODS and } \\
\text { maximal strength. The regression } \\
\text { analysis revealed significant multiple } \\
\text { correlation between predictors and } \\
\text { the criterion ( } \mathrm{R}=0.41 ; \mathrm{p}<0.001 \text { ); the } \\
\text { amount of explained variance of the } \\
\text { agility performance by the strength } \\
\text { factors was low ( } 17 \% \text { ). Leg extensor } \\
\text { strength qualities are poor predictors } \\
\text { of agility performance. }\end{array}$ \\
\hline $\begin{array}{l}\text { Sporis et al., } \\
2010\end{array}$ & $\begin{array}{l}\mathrm{n}=150, \\
\text { Male, elite junior } \\
\text { soccer players, } \\
\text { Age: } 19.1 \pm 0.6 \\
\text { years }\end{array}$ & $\begin{array}{l}\text { Slalom test } \\
\text { CODS sprint } 4 \times 5 \\
\mathrm{~T} \text { test } \\
\text { Sprint with } 90^{\circ} \\
\text { turns } \\
\text { Sprint with } 180^{\circ} \\
\text { turns } \\
\text { SBF }\end{array}$ & $\begin{array}{l}\text { PCA, } \\
\text { Kaiser- } \\
\text { Guttman } \\
\text { criterion }\end{array}$ & $\begin{array}{l}\text { It was concluded that of the } 6 \text { agility } \\
\text { tests used in this study, the SBF, T- } \\
\text { test, and Sprint with } 180^{\circ} \text { turns were } \\
\text { the most reliable and valid tests for } \\
\text { estimating agility of soccer players. } \\
\text { PCA resulted in the extraction of two } \\
\text { significant components that } \\
\text { explained } 56.99 \% \text { of the total } \\
\text { variance. SBF test }(\mathrm{r}=0.78) \text { had the } \\
\text { best factorial validity among all } \\
\text { analyzed agility tests, and } \\
\text { comparable factorial validity was } \\
\text { observed for the T-test }(\mathrm{r}=0.73) \text { and } \\
\text { Sprint with } 180^{\circ} \text { turns }(\mathrm{r}=0.73) \text { test. }\end{array}$ \\
\hline
\end{tabular}

CODS $=$ change of direction speed, ${ }^{*}$ physical education student, $1 R M=$ one repetition maximum, $S S C=$ stretch shortening cycle,$C J=$ countermovement jump, $S L J=$ standing long jump, $S J=$ squat jump, $D J=$ drop jump, $L S=$ lateral stepping, $S q=$ squat, $S B F=$ sprint with backward and forward running, $P C A=$ principal component analysis, $E F A=$ factor analysis - exploratory approach 


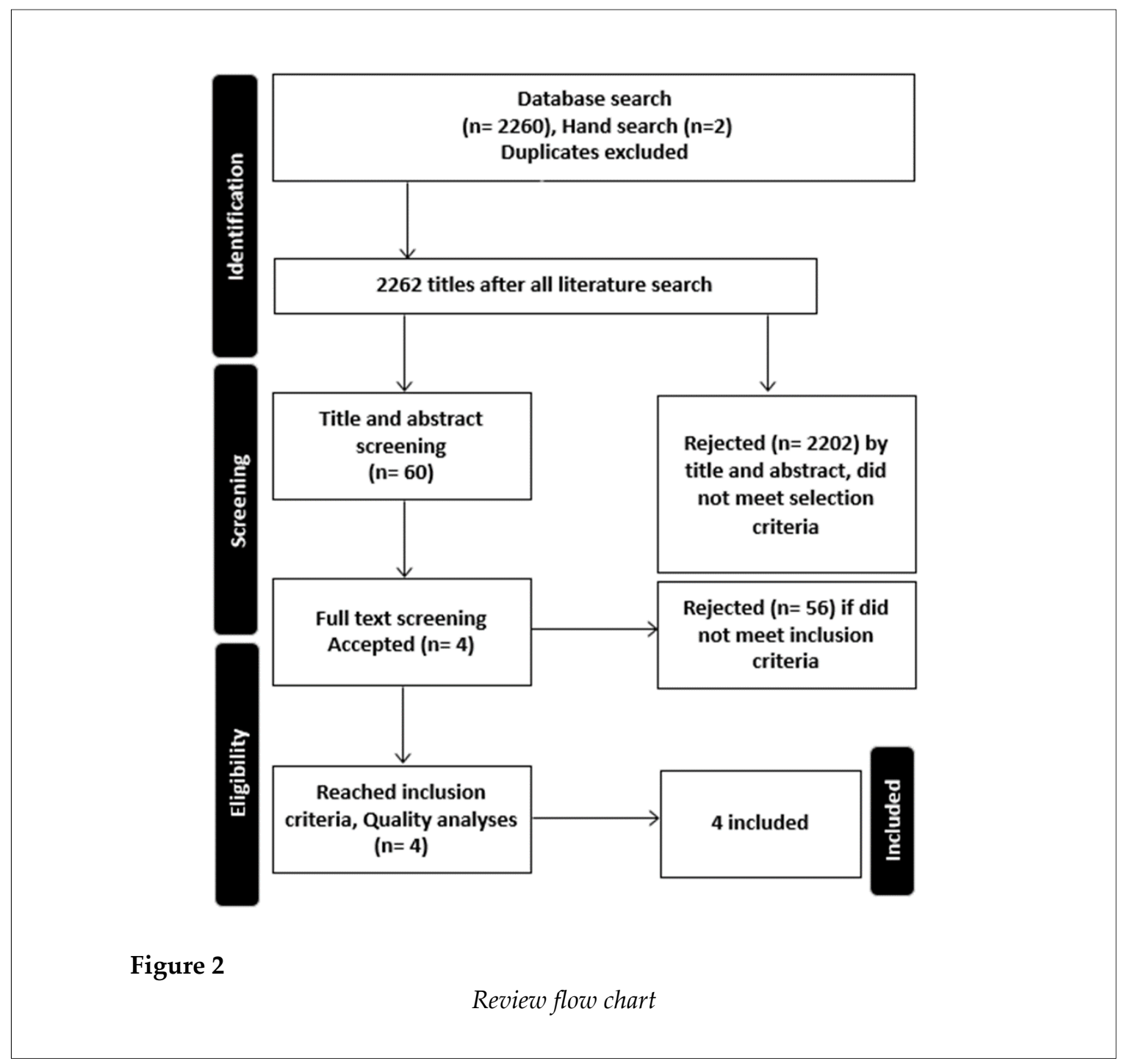

PCA is used mainly when it is necessary to reduce a large number of indicators to a smaller and more manageable amount of directly measured tests for subsequent analysis. In our review, we found only one study (Markovic et al., 2007) that used a common factor model from SEM, specifically the exploratory factor analyses (EFA) approach. However, no research has verified the structure of agility using SEM, such as confirmatory factor analysis or structural regression models, although many methodologists (McDonald, 1999; Muthén and Muthén, 2010) showed that approaches from a family of SEM enable researchers to specify relationships between latent variables (constructs) and a set of measures as well as to determine the relationships between constructs. Consequently, a large number of studies described the internal relationship between agility tests, which is the relationship between a dependent variable and defined independent variables. Certainly this situation gives an apparent chance for developing new agility tests, which will probably provide a sufficient correlation with previously accepted tests. However, adding or removing different tests cannot explain the basic principles that make up agility performance. Therefore, it would be highly desirable to verify and establish a factorial model of agility by second generation data analysis techniques (Bagozzi and Fornell, 1982) to which SEM belongs.

Despite the theoretical background, the original empirical model of agility (compounding from perceptual and decision-making skills and change-of-direction speed) might seem to be appropriate, but its usefulness is diminished by the large number of agility test choices that do not have a quantified hierarchy. For example, it has 
been reported that CODS is often used in team sports; however, performance in sports or activities that involve CODS does not predict (perhaps not with a strong relationship) complex agility performance (Henry et al., 2011; Serpell et al., 2010; Sheppard et al., 2006). One of the results from the present study is that only tests of CODS and not complex agility have been analyzed to determine the variance in CODS performance. The study of Stewart et al. (2014) concluded that common CODS tests (Illinois, L-Run, Pro-Agility, T-test, and 505 agility) were highly reliable and valid measures of CODS in collegiate athletes performing in invasive games and could explain $89.5 \%$ of the CODS latent variable (factor) variance. Therefore, performance in these tests is a suitable and sensitive assessment of CODS. As a result, the above mentioned specific combination of selected CODS tests is sufficient to assess the CODS performance of athletes at the collegiate level who perform in different invasive games. On the other hand, if elite athletes representing one sport discipline are tested, the need for specific CODS tests increases. The study of Sporis et al. (2010) showed that sprinting with backward and forward running had greater factorial validity for CODS than a slalom test, a CODS sprint $4 \times 5 \mathrm{~m}$, a T-test and a sprint with 90 or $180^{\circ}$ turns in elite soccer players, but those tests could explain only $57 \%$ of COD variance (Table 1). These findings support the empirical knowledge that higher performance levels require more specific tests of agility involving CODS. Furthermore, in the future, the structure of the specific agility tests for elite athletes should be estimated independently from general agility tests.

Other studies have confirmed that within the agility structure, there is a CODS independent factor (Marković et al., 2007; Salaj and Markovic, 2011; Zajac et al., 2014). Specifically, from the results of EFA, Markovic et al. (2007) revealed three other independent factors (in addition to CODS), namely, explosive strength, elastic strength and maximum strength. However, according to their results, these factors explained only $17 \%$ of CODS performance. Later, Salaj and Markovic (2011) found that other independent factors could be determined, namely, sprinting ability, concentric/slow stretch and shortening cycle jumping ability and fast stretch and shortening cycle jumping ability, which together with CODS explained $80 \%$ of the test variance. These results indicated that sprinting along with jumping ability could better determine CODS than explosive and maximum strength in collegiate athletes.

Considering the agility concept, we can estimate that only CODS and perhaps some of the technical and physical determinants have been appropriately analyzed in current literature (Figure 2). On the other hand, some studies have focused on creating complex agility tests that also include cognitive or decision-making aspects (Serpell et al., 2011; Czuba et al., 2013; Spiteri et al., 2014a); thus, their testing approach should be incorporated into factor analyses of agility.

\section{Conclusion}

Currently, there is poor quantitative evidence validating the previously established factorial model of agility. Only four studies used exploratory techniques such as PCA or EFA, and no study used structural equation modeling or confirmatory approaches for determining the relationships between indicators and concepts within the agility factor structure. Therefore, we strongly suggest that future research should verify and establish a factorial agility model using a second generation data analysis technique to which the family of structural equation modelling (SEM) belongs. From the whole structure of agility, only CODS tests and some of their subtests have been appropriately analyzed. The combination of common CODS tests is reliable and useful to estimate CODS performance in subelite athletes; however, for elite athletes, specific CODS tests that are relevant to the needs of particular sport disciplines must be constructed. Sprinting and jumping tests are stronger factors for CODS than explosive and maximal strength tests.

Future research should focus on the following aspects:

1. Performing factor analyses of the agility factor structure for each agility classification.

2. Identification of independent factors for general and sport-specific agility tests.

3. Identification of sport-specific agility tests for elite athletes.

4. Analysis of the factorial strength of complex agility tests such as the test of reactive agility. 


\section{Acknowledgements}

This study was supported by research grants from Czech Science Foundation and NO. 16-13750S and by a grants of Ministry of Science and Higher Education of Poland (NRSA3 03953 and NRSA4 040 54).

\section{References}

Bagozzi RP, Fornell C. Theoretical concepts, measurements, and meaning. A second generation of multivariate analysis, 1982; 2: 5-23

Czuba M, Zając A, Maszczyk A, Roczniok R, Poprzęcki S, Garbaciak W, Zając T. The Effects of High Intensity Interval Training in Normobaric Hypoxia on Aerobic Capacity in Basketball Players. J Hum Kinet, 2013; 39(1): 103-114

Delextrat A, Grosgeorge B, Bieuzen F. Determinants of performance in a new test of planned agility for young elite basketball players. Int J Sports Physiol Perform, 2015; 10: 160-165

Fabrigar LR, Wegener DT, MacCallum RC, Strahan EJ. Evaluating the use of exploratory factor analysis in psychological research. Psychol Meth, 1999; 4: 272

Gabbett TJ, Kelly JN, Sheppard JM. Speed, change of direction speed, and reactive agility of rugby league players. J Strength Condit Res, 2008; 22: 174-181

Hachana Y, Chaabène H, Nabli MA, Attia A, Moualhi J, Farhat N, Elloumi M. Test-retest reliability, criterion-related validity, and minimal detectable change of the Illinois agility test in male team sport athletes. J Strength Condit Res, 2013; 27: 2752-2759

Henry G, Dawson B, Lay B, Young W. Validity of a reactive agility test for Australian football. International journal of sports physiology and performance, 2011; 6(4): 534-545

Hox J, Bechger T. An introduction to structural equation modeling. Family Science Rewiew, 1998; 11: 354-373

Jeffreys I. A task-based approach to developing context-specific agility. J Strength Condit Res, 2011; 33: 52-59

Kline RB. Principles and practice of structural equation modeling. New York, London: Guilford Press; 2011

MacCallum RC, Austin JT. Applications of structural equation modeling in psychological research. Annu Rev Psychol, 2000; 51: 201-226

Magiera A, Roczniok R, Maszczyk A, Czuba M, Kantyka J, Kurek P. The Structure of Performance of a Sport Rock Climber. J Hum Kinet, 2013; 36: 107-117

Marković G, Sekulić D, Marković M. Is agility related to strength qualities?-Analysis in latent space. Collegium antropologicum, 2007; 31: 787-793

Marsh HW, Lüdtke O, Muthén B, Asparouhov T, Morin AJ, Trautwein U, Nagengast B. A new look at the big five factor structure through exploratory structural equation modeling. Psychol Assess, 2010; 22: 471

McDonald RP. Test theory: A unified approach. Mahwah, NJ: Lawrence Erlbaum; 1999

McNeill LH, Wyrwich KW, Brownson RC, Clark EM, Kreuter MW. Individual, social environmental, and physical environmental influences on physical activity among black and white adults: a structural equation analysis. Ann Behav Med, 2006; 31: 36-44

Metikoš D, Marković G, Prot F, Jukić I. Latent structure of agility obtained by a battery of tests. Kinesiology, 2003; 35: 14-29

Mikolajec K, Maszczyk A, Zajac T. Game Indicators Determining Sports Performance in the NBA. J Hum Kinet, 2013; 37: 145-151

Moher D, Schulz KF, Simera I, Altman DG. Guidance for developers of health research reporting guidelines. PLoS medicine, 2010; 7: e1000217

Muthén LK, Muthén BO. 1998-2010 Mplus user's guide. Muthén and Muthén, 2010

Pauole K, Madole K, Garhammer J, Lacourse M, Rozenek R. Reliability and validity of the T-test as a measure of agility, leg power, and leg speed in college-aged men and women. J Strength Condit Res, 2000; 14: 443-450 
Raya MA, Gailey RS, Gaunaurd IA, Jayne DM, Campbell SM, Gagne E, Manrique PG, Muller DG, Tucker C. Comparison of three agility tests with male servicemembers: Edgren Side Step Test, T-Test, and Illinois Agility Test. J Rehabil Res Dev, 2013; 50: 951-60

Salaj S, Markovic G. Specificity of jumping, sprinting, and quick change-of-direction motor abilities. J Strength Condit Res, 2011; 25: 1249-1255

Serpell BG, Ford M, Young WB. The development of a new test of agility for rugby league. J Strength Condit Res, 2010; 24: 3270-3277

Serpell BG, Young WB, Ford M. Are the perceptual and decision-making components of agility trainable? A preliminary investigation. J Strength Condit Res, 2011; 25: 1240-1248

Sheppard J, Young WB, Doyle T, Sheppard T, Newton RU. An evaluation of a new test of reactive agility and its relationship to sprint speed and change of direction speed. J Sci Med Sport, 2006; 9: 342-349

Sheppard JM, Dawes JJ, Jeffreys I, Spiteri T, Nimphius S. Broadening the view of agility: A scientific review of the literature. Journal of Australian Strength and Conditioning, 2014; 22: 6-25

Sheppard JM, Young WB. Agility literature review: Classifications, training and testing. J Sports Sci, 2006; 24: 919-932

Schreiber JB, Nora A, Stage FK, Barlow EA, King J. Reporting structural equation modeling and confirmatory factor analysis results: A review. J Educ Res, 2006; 99: 323-338

Spiteri T, Hart NH, Nimphius S. Offensive and defensive agility: a sex comparison of lower body kinematics and ground reaction forces. J Appl Biomech, 2014a; 30: 514-520

Spiteri T, Nimphius S, Hart NH, Specos C, Sheppard JM, Newton RU. Contribution of strength characteristics to change of direction and agility performance in female basketball athletes. J Strength Condit Res, 2014b; 28: 2415-2423

Sporis G, Jukic I, Milanovic L, Vucetic V. Reliability and factorial validity of agility tests for soccer players. J Strength Condit Res, 2010; 24: 679-686

Stewart PF, Turner AN, Miller SC. Reliability, factorial validity, and interrelationships of five commonly used change of direction speed tests. Scand J Med Sci Sports, 2014; 24: 500-506

Tabachnick BG, Fidell LS, Osterlind SJ. Using multivariate statistics. 2001

Ullman S. In BG Tabachnick, \& LS Fidell (Eds.), Using multivariate statistics (pp. 653-771 ed., p. 966). Needham Heights, MA: Allyn and Bacon; 2001

Young KP, Haff GG, Newton RU, Sheppard JM. Reliability of a novel testing protocol to assess upper-body strength qualities in elite athletes. Int J Sports Physiol Perform, 2014; 9: 871-875

Young W, James R, Montgomery I. Is muscle power related to running speed with changed of direction? J Sports Med Phys Fitness, 2002; 42: 282

Young WB, Dawson B, Henry GJ. Agility and change-of-direction speed are independent skills: Implications for training for agility in invasion sports. International Journal of Sports Science and Coaching, 2015; 10: 159-169

Zajac A, Poprzecki S, Maszczyk A, Czuba M, Michalczyk M, Zydek G. The effects of a ketogenic diet on exercise metabolism and physical performance in off-road cyclists. Nutrients, 2014;6(7): 2493-508

\section{Corresponding author:}

\section{Petr Stastny Ph.D.}

Address: Charles University in Prague, Faculty of Physical Education and Sport

Jose Martiho 31, Prague 6, 16252, Czech Republic

Scopus Author ID: 56545285000; Orcid ID: 0000-0003-2841-374X

Phone: +420777198764

Email: stastny@ftvs.cuni.cz 